Article

\title{
Growth and Ginsenosides Content of Ginseng Sprouts According to LED-Based Light Quality Changes
}

\author{
Yoon-Jeong Kim 1,2,+, Thi Kim Loan Nguyen ${ }^{1,2,+}$ and Myung-Min Oh 1,2,* \\ 1 Division of Animal, Horticultural and Food Sciences, Chungbuk National University, Cheongju 28644, \\ Korea; aga903@naver.com (Y.-J.K.); kimloanmt@gmail.com (T.K.L.N.) \\ 2 Brain Korea 21 Center for Bio-Health Industry, Chungbuk National University, Cheongju 28644, Korea \\ * Correspondence: moh@cbnu.ac.kr; Tel.: +82-43-261-2530 \\ + These authors contributed equally to this work.
}

Received: 17 November 2020; Accepted: 14 December 2020; Published: 16 December 2020

\begin{abstract}
This study investigated growth and ginsenosides content of ginseng sprouts under various light spectra. One-year-old ginseng seedlings were cultivated under various light treatments including: monochromatic (red (R), green (G), and blue (B)), various RB and RGB combinations, white (fluorescent lamps (FL) and natural white (NW)), and supplemental far red (FR). $\mathrm{R}$ and high $\mathrm{R}$ ratio increased growth characteristics of ginseng sprouts (excepted for root dry weight). The replacement of $\mathrm{G}$ for $\mathrm{B}$ in RGB group and W group did not increase the growth, and supplemental FR increased shoot and root fresh weights, total fresh weight, and leaf area. $\mathrm{R}$ had 1.5 times higher photosynthetic rate compared to $B$ and $G$, and $R_{8} G_{1} B_{1}$ and $R_{9} G_{1} B_{0}$ showed the highest values in RGB group; whereas the $R B, W$, and FR groups did not enhance photosynthetic rate. $\mathrm{B}$ and high $\mathrm{B}$ ratio increased shoot saponin and ginsenosides, total saponin and ginsenosides contents. Total saponin content in shoot was 4.4 times higher than that in root. The supplemental FR enhanced both total saponin and ginsenosides contents. In conclusion, NW + FR showed the highest total fresh weight, saponin and ginsenosides contents among all treatments, suggesting that supplementation of FR has a positive effect on ginseng sprouts grown in plant factories.
\end{abstract}

Keywords: ginsenosides; light quality; Panax ginseng; plant factory; saponin content

\section{Introduction}

Panax ginseng is one of the most important medicinal plants and has commercially been cultivated in Asian countries such as Korea, China, and Vietnam. Ginsenosides are known as the major components of ginseng, which possesses numerous physiological and pharmacological effects such as anti-cancer, anti-stress, neuro-protective, and anti-diabetic [1-3]. Ginseng root is normally harvested between the fourth and sixth year of growth, which has been widely used for manufacturing health supplements and cosmetics. The older the root with increasing the distribution of fine root and lateral root is, the higher concentration of ginsenosides is [4]. However, many studies recently reported that ginsenosides content is higher in the leave than in the root cultivated for the same duration, and 1-year-old ginseng leave have the highest ginsenosides content $[5,6]$. Ginseng leave becomes an excellent source for food and industrial values, which raises the interest of producers on ginseng sprout cultivation for leaf production. Ginseng sprouts can be harvested after approximately 3 to 6 weeks of cultivating and are recognized as a crop with high economic efficiency and potential value.

Most of the ginseng sprouts are grown in greenhouses, and the ginseng sprouts values have more than twice the sales of ginseng seedlings. Recently, ginseng has been grown in hydroponic systems 
with a short-term cultivation, which produces higher concentrations of ginsenosides in leave and root over a short period [7]. Comparing to traditional farms and greenhouses, plant factories with artificial light (PFALs) can precisely control the environmental cultivation conditions without being affected by changes in the external environment. Moreover, it is possible to plan year-round production in PFALs, which is feasible to produce high quality crops in large quantities annually [8]. Therefore, the cultivation of ginseng sprouts in PFALs has the potential to increase quality as well as economic and industrial values by improving growth and ginsenosides content.

Light (light intensity, photoperiod, and light quality) is a crucial factor affecting the crop yield and quality [9-12]. Since PFALs use artificial light sources instead of sunlight, the electricity consumption of plant factories is a substantial cost [13]. Therefore, determining the optimal light conditions can increase energy use efficiency through productivity enhancement, securing the economic efficiency of PFALs. In particular, light quality has a major influence on plant growth, photosynthesis, and the production of health-promoting phytochemicals [14-16]. Among the photoreceptors in plants, phytochromes (red and far-red wavelengths), cryptochromes and phototropins (blue or UV-A wavelengths) recognize the stimulation at each wavelength and affect the plant growth and development through complex light signals $[17,18]$. Many previous studies reported the positive effect of light quality on leafy vegetables grown in PFALs and proved that the proper light quality can improve crop productivity and quality by inducing changes in photosynthesis and photomorphogenesis [19-21]. However, there is little research about the effect of light quality on ginseng sprouts; therefore, it is necessary to explore the influence of light quality on ginseng sprouts to establish proper light conditions for cultivating ginseng sprouts in PFALs.

\section{Materials and Methods}

\subsection{Plant Materials and Growth Conditions}

One-year-old autumn ginseng seedlings (Panax ginseng Meyer (ginseng farmhouse, Jinju, Korea)) stored at a low temperature, which had main tap root with small emerging shoot, were selected with the similar size, length, and weight. The average fresh weight of the seedlings was $0.61 \pm 0.1 \mathrm{~g}$. The seedlings were planted in 50-cell trays $(27 \times 58 \times 8 \mathrm{~cm},(\mathrm{~L} \times \mathrm{W} \times \mathrm{H}))$ containing a ginseng-exclusive medium (Shinsung Mineral Co., Ltd., Seongnam, Korea). These planted seedlings were cultivated in a plant factory under natural white LEDs light, temperature $15^{\circ} \mathrm{C}$, and relative humidity $70 \%$ for emerging the sprouts. After 2 weeks of planting, the sprouts with unfold foliation were treated with different light quality treatments, and the growing conditions were changed to a temperature $23^{\circ} \mathrm{C}$, relative humidity $60 \%$, and $\mathrm{CO}_{2} 400 \mu \mathrm{mol} \mathrm{mol}^{-1}$. Nutrient solution for ginseng sprouts (National Institute of Horticultural and Herbal Science, EC $0.8 \mathrm{dS} \mathrm{m}^{-1}, \mathrm{pH} 5.5$ ) was supplied with $0.5 \mathrm{~L}$ of bottom watering once every $3-4$ days for 5 weeks after planting.

\subsection{Light Treatments}

Monochromatic group (mono group) with red (R, $656 \mathrm{~nm})$, green $(\mathrm{G}, 520 \mathrm{~nm})$, and blue (B, $451 \mathrm{~nm})$ LEDs (L-PEC, Jeonju, Korea), a RB combination group $\left(\mathrm{R}_{6} \mathrm{~B}_{4}, \mathrm{R}_{7} \mathrm{~B}_{3}, \mathrm{R}_{8} \mathrm{~B}_{2}\right.$, and $\mathrm{R}_{9} \mathrm{~B}_{1}$; base on chip number), and a RGB combination group $\left(R_{5} G_{1} B_{4}, R_{6} G_{1} B_{3}, R_{7} G_{1} B_{2}, R_{8} G_{1} B_{1}\right.$, and $\left.R_{9} G_{1} B_{0}\right)$ were used as light spectral treatments in this study (Figure S1). The white group (W group) was treated with fluorescent lamps (FL; HYG-FPL 36 W-R; Nam Yung, Seoul, Korea) and white LEDs (natural white, NW, Bissol LED, Seoul, Korea). The supplemental far-red group (FR group) was further investigated in $\mathrm{R}_{6} \mathrm{G}_{1} \mathrm{~B}_{3}$ and NW using far-red LEDs (Itswell, Incheon, Korea; peak $740 \mathrm{~nm}$ ), and the R/FR ratio of $\mathrm{R}_{6} \mathrm{G}_{1} \mathrm{~B}_{3}+\mathrm{FR}$ and $\mathrm{NW}+\mathrm{FR}$ was adjusted to 1.2. In total, sixteen light treatments were created and tested simultaneously in a plant factory. The light period and photosynthetic photon flux density (PPFD) were set at $16 \mathrm{~h}$ and $80 \mu \mathrm{mol} \mathrm{m}{ }^{-2} \mathrm{~s}^{-1}$, respectively. Light spectral distributions were measured using a spectroradiometer (JAZ-EL 200, Ocean optics, Dunedin, FL, USA) by dividing the cultivation area $[54 \times 58 \mathrm{~cm}(\mathrm{~L} \times \mathrm{W})]$ into 6 areas for each light treatment based on the height of the canopy (Figure 1). 
As the canopy height of the crops for each treatment was differentiated, the distance between the crop and the light source was kept constant to remove the factor of change in light intensity according to the irradiation distance from the light source. To minimize experimental error due to the non-uniform distribution of the irradiated light source, the plants were rotated every 1-2 days.

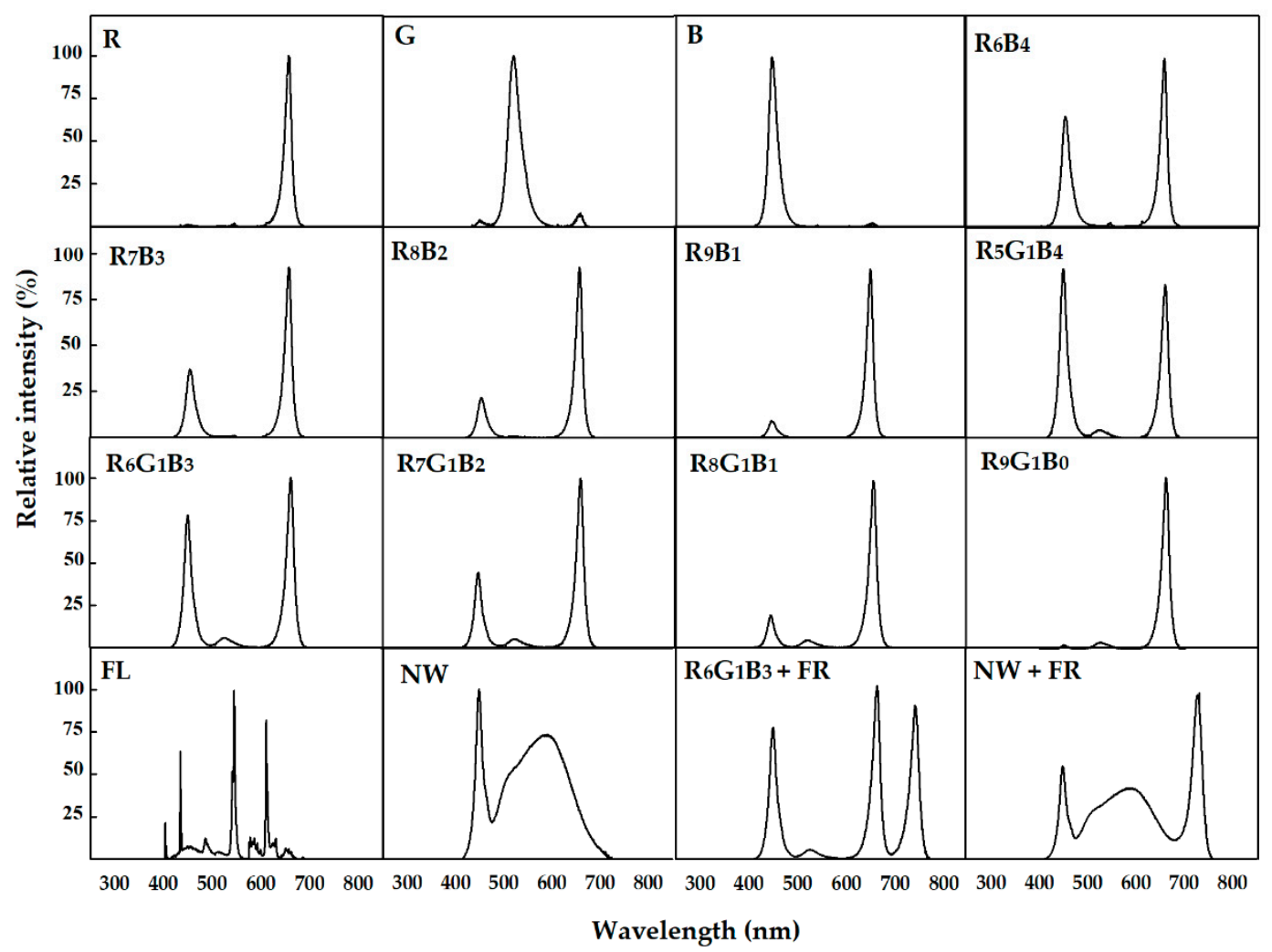

Figure 1. Relative spectral distribution of sixteen light treatments with red LEDs (R), green LEDs $(\mathrm{G})$, blue LEDs (B), fluorescent lamps (FL), natural white LEDs (NW), and far-red LEDs (FR) used in this study.

\subsection{Growth Characteristics}

To compare the growth of ginseng sprouts under various light quality treatments, growth characteristics were measured at 5 weeks after planting. The shoot and root were separated by cutting the area around the rhizome with a knife, and the fresh weights of the shoot and root were measured using an electronic scale (Si-234, Denver Instrument, Bohemia, NY, USA). The length from the shoot of the rhizome to the part where the stem was split was measured by a ruler, and the leaf area was measured using a leaf area meter (LI-2050A, Li-Cor, Lincoln, NE, USA). T/R ratio was defined as the fresh weight ratio of top (shoot) to root. The shoot and root were freeze-dried for more than $96 \mathrm{~h}$ in a freeze dryer (Alpha 2-4 LSC plus, CHRIST, Osterode am Harz, Germany) at $-75{ }^{\circ} \mathrm{C}$, and then the dry weights of shoot and root were measured with an electronic scale.

\subsection{Photosynthetic Parameters}

After 4 weeks of planting, the photosynthetic rate, transpiration rate, and conductance of $\mathrm{H}_{2} \mathrm{O}$ of the fully extended leave were measured using a photosynthetic machine (LI-6400, LI-COR, Lincoln, NE, USA) equipped with a clear bottom chamber $(2 \times 3 \mathrm{~cm})(\mathrm{LI}-6400-08, \mathrm{Li}-\mathrm{Cor}$, Lincoln, NE, USA). The conditions of the measurement chamber were set to $400 \mu \mathrm{mol} \mathrm{mol}{ }^{-1} \mathrm{CO}_{2}, 23{ }^{\circ} \mathrm{C}$ air temperature, and $300 \mu \mathrm{mol} \mathrm{s}{ }^{-1}$ flow rate. The photosynthetic parameters were measured at a point that light intensity was $80 \mu \mathrm{mol} \mathrm{m} \mathrm{m}^{-2} \mathrm{~s}^{-1}$ under each light source, and the measurements were performed for 
3-6 $\mathrm{h}$ after the light was turned on. SPAD value reflecting relative chlorophyll content was measured by a portable chlorophyll meter (SPAD-502, Konica Minolta, Tokyo, Japan).

\subsection{Total Saponin Content}

To analyze the saponin content, the shoot and root were separately harvested at 5 weeks after planting and freeze-dried for $96 \mathrm{~h}$ in a freeze dryer. All samples were ground to powder using a mill (Tube mill control, IKA, Wilmington, NC, USA). For saponin extraction, approximately $100 \mathrm{mg}$ of dry powder of each sample and $5 \mathrm{~mL} 1-\mathrm{BuOH}(99.8 \%, v / v)$ were added to a $15 \mathrm{~mL}$ conical tube and then vortexed for $10 \mathrm{~s}$. Thereafter, the extracted samples were incubated at $4{ }^{\circ} \mathrm{C}$ for more than $24 \mathrm{~h}$ and then sonicated in a sonication bath at $50{ }^{\circ} \mathrm{C}$ for $60 \mathrm{~min}$ (SK5210HP, KUDOS, Shanghai, China). After centrifuging $(2195 \times g)$ at $4{ }^{\circ} \mathrm{C}$ for $15 \mathrm{~min}$, the supernatant was evaporated at $40-50{ }^{\circ} \mathrm{C}$ for approximately $2 \mathrm{~h}$ using a nitrogen evaporator (N-EVAP 111, Organomation, Berlin, MA, USA), and then $5 \mathrm{~mL}$ of $\mathrm{MeOH}(99 \%, v / v)$ was added. After that, the total saponin content was analyzed according to a method described by [22]. The standard curve of total saponin content was obtained using the ginsenoside standard Re (ASB-00007210-005, ChromaDex, Los Angeles, CA, USA). Shoot and root saponin contents were expressed as milligrams of saponin per gram dry weight of shoot and root $\left(\mathrm{mg} \mathrm{g}^{-1}\right)$. Total saponin content was calculated by the sum of the saponin content per shoot dry weight and the saponin content per root dry weight, and this value was expressed as milligrams (mg).

\subsection{Ginsenosides Content}

Dry powder (45 mg) of each sample was mixed with $4.5 \mathrm{~mL}$ of ethanol and extracted in a sonication bath at $27-30^{\circ} \mathrm{C}$ for $1 \mathrm{~h}$. The extract was centrifuged at $2195 \times g$ at $20^{\circ} \mathrm{C}$ for $10 \mathrm{~min}$, and the supernatant was used for analysis. After evaporating the solvent of the supernatant by a nitrogen evaporator, $2.5 \mathrm{~mL}$ of distilled water and $2.5 \mathrm{~mL}$ of diethyl ether $(99.5 \%, v / v)$ were added, mixed, and then incubated for $30 \mathrm{~min}$. The supernatant diethyl ether was removed from the two layers, and the process was repeated. After that, $1 \mathrm{~mL}$ distilled water and $1 \mathrm{~mL}$ 1-butyl alcohol $(99.8 \%, v / v)$ were added and mixed, followed by incubating for $30 \mathrm{~min}$. The upper layer was transferred to a new tube, and the process was repeated. After evaporating the supernatant with a nitrogen evaporator, $600 \mu \mathrm{L}$ of methanol was added and filtered using a syringe filter (BS20-PC13, BioFACT, Daejeon, Korea).

The ginsenosides content was measured using a HPLC system (YL9100, Youngin Chromass, Anyang, Korea) equipped with a UV/VIS detector (YL9120, Youngin Chromass, Anyang, Korea). A Fortis C18 column (F18-050905, $250 \times 4.6 \mathrm{~mm}, 5 \mu \mathrm{M}$, Chromex Scientific, Dronfield, UK) was used, and samples were injected in $20 \mu \mathrm{L}$ increments. Solvent A was $100 \%$ acetonitrile, and solvent B was deionized water. The flow rate of the mobile phases was maintained at $0.6 \mu \mathrm{L} \mathrm{min}{ }^{-1}$, and the column temperature was $35^{\circ} \mathrm{C}$. Ginsenosides were detected at an absorbance of $203 \mathrm{~nm}$. The ratio of solvent A was as follows; $30 \%$ (0-10 $\mathrm{min}$ ), 30-40\% (10-50 $\mathrm{min}$ ), 40-80\% (50-55 $\mathrm{min}), 80-20 \%$ (55-61 $\mathrm{min}$ ) and $20-30 \%$ (61-70 $\mathrm{min}$ ). The commercial grade ginsenosides consisting of protopanaxadiol ( $\mathrm{PD} ; \mathrm{Rb}_{1}, \mathrm{Rb}_{2}$, $\mathrm{Rc}$, and $\mathrm{Rd}$ ) and protopanaxatriol (PT; $\mathrm{Rg}_{1}, \mathrm{Rg}_{2}, \mathrm{Rg}_{3}, \mathrm{Re}$, and $\mathrm{Rf}$ ) were purchased from ChromaDex (Los Angeles, CA, USA). Shoot and root ginsenosides contents were expressed as milligrams of ginsenosides per gram dry weight of shoot and root $\left(\mathrm{mg} \mathrm{g}^{-1}\right)$. Total ginsenosides content was calculated as above total saponin content, and this value was expressed as milligrams (mg).

\subsection{Statistical Analysis}

The growth characteristics and photosynthetic parameters were measured in 10 and 4 replicates, respectively. Total saponin and ginsenosides contents were measured in 6 and 5 replicates, respectively, using freeze-dried powder by combining 10 samples per treatment. For statistical analysis, ANOVA was performed using the SAS statistical program (Statistical Analysis System, 9.4 Version, SAS Institute, Cary, NC, USA). Significant differences in all treatments were verified at $p<0.05$, using Duncan's multiple range test. Graphs were created using the SigmaPlot program (Exact Graphs and Data Analysis, 12 Version, Systat Software Inc., San Jose, CA, USA). 


\section{Results}

\subsection{Growth Characteristics}

In the monochromatic group, the growth characteristics of ginseng sprouts was highest under $\mathrm{R}$ and was lowest under B (excepted for root fresh weight); particularly, R exhibited 2.0 times higher shoot fresh weight and T/R ratio and 3.0 times higher stem length compared to B. Meanwhile, G showed lower shoot fresh weight, $\mathrm{T} / \mathrm{R}$ ratio, stem length, and no significant difference in root fresh weight, total fresh weight, and leaf area comparing to $\mathrm{R}$ light (Figure 2). The combination of RB and RGB groups showed different effects on growth parameters of ginseng sprouts. In the RB group, $R_{8} B_{2}$ resulted in higher shoot fresh weight compared to $R_{6} B_{4}$ and $R_{7} B_{3}$, whereas in the RGB group, $\mathrm{R}_{9} \mathrm{G}_{1} \mathrm{~B}_{0}$ exhibited the highest value (Figure $2 \mathrm{~A}$ ). There was no significant difference in root fresh weight among the $R B$ group, while in the RGB group, $R_{9} G_{1} B_{0}$ showed a lowest value (Figure $2 B$ ). The higher ratio of $R$ resulted in a higher $T / R$ ratio, and the highest value was obtained in $R_{9} G_{1} B_{0}$ (Figure $2 D$ ). $R_{8} B_{2}$ had the highest leaf area in the RB group, and in the RGB group, $R_{9} G_{1} B_{0}$ showed the lowest value (Figure $2 E$ ). Stem length under $R_{9} B_{1}$ was higher compared to $R_{7} B_{3}$ in the $R B$ group, and $R_{9} G_{1} B_{0}$ showed the highest value among treatments in the RGB group (Figure $2 F$ ). There were no significant differences in all of growth characteristics between FL and NW treatments. Both the supplement FR treatments $\left(\mathrm{R}_{6} \mathrm{G}_{1} \mathrm{~B}_{3}+\mathrm{FR}\right.$ and $\left.\mathrm{NW}+\mathrm{FR}\right)$ had a significantly higher shoot and root fresh weights, total fresh weight, and leaf area compared to those under those in the respective treatments without FR $\left(\mathrm{R}_{6} \mathrm{G}_{1} \mathrm{~B}_{3}\right.$ and NW) (Figure $\left.2 \mathrm{~A}-\mathrm{C}, \mathrm{E}\right)$. Overall, $\mathrm{R}$ and the supplement of FR in NW showed the efficient improvement of ginseng sprout growth.

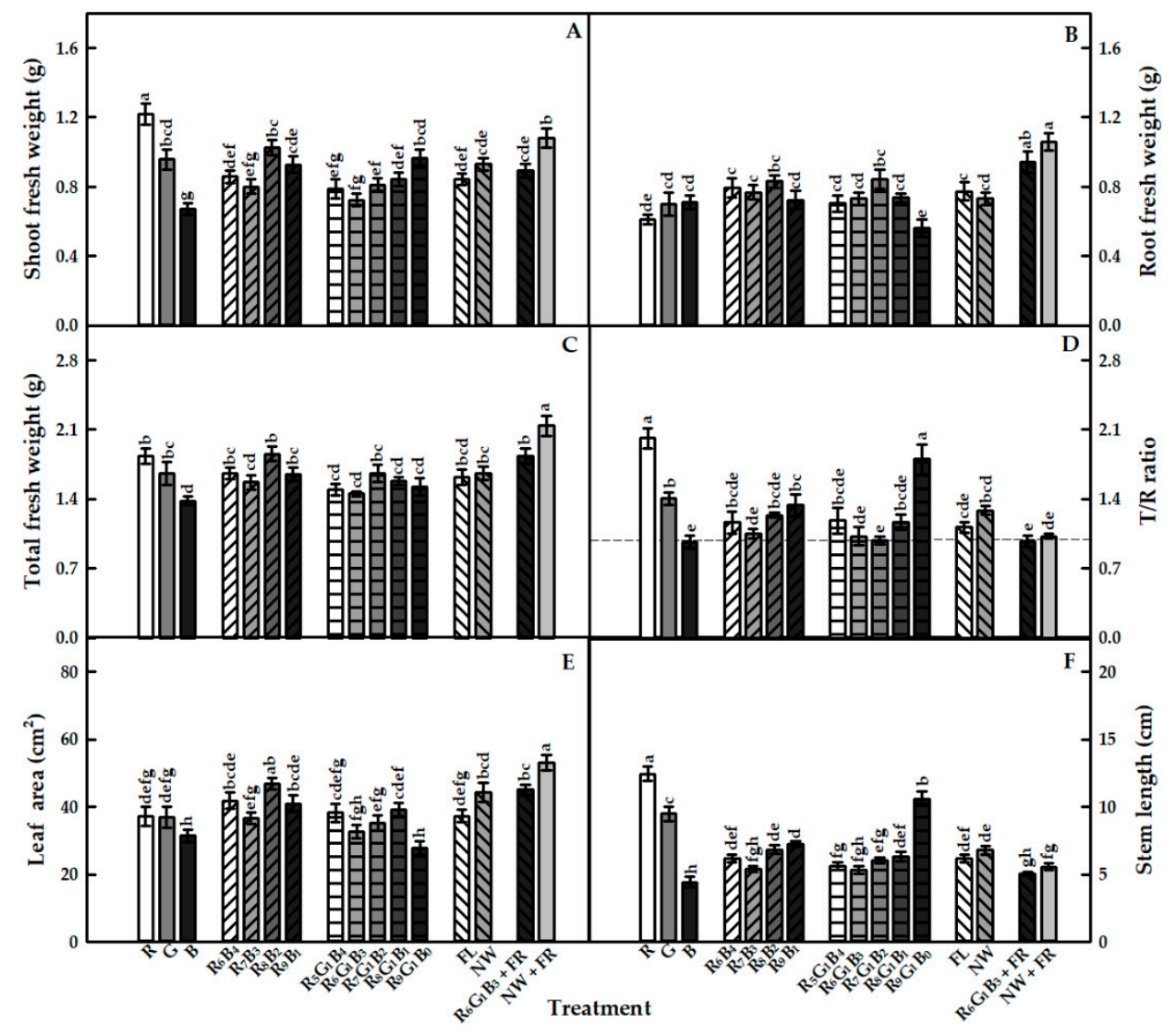

Figure 2. Shoot fresh weight (A), root fresh weight (B), total fresh weight $(\mathbf{C}), \mathrm{T} / \mathrm{R}$ ratio (D), leaf area (E) and stem length (F) of ginseng sprouts grown under various light treatments for 5 weeks. Different letters indicate significant differences at $p<0.05(n=10)$. The dashed line in figure (D) indicates a T/R ratio of 1 . 


\subsection{Photosynthetic Parameters}

The result of SPAD value presented an opposite trend to that of growth characteristics. The SPAD value was slightly higher in $B$ than in $R$ and $G$, and in RB and RGB groups, the higher $B$ ratio resulted in the higher value (Figure $3 A$ ). In the $W$ group, this value in FL was higher than that in NW, while in the supplement $F R, R_{6} G_{1} B_{3}+F R$ resulted in a lower value than $R_{6} G_{1} B_{3}$, and no significant difference in SPAD was observed between NW + FR and NW. Photosynthetic rate of plants under R was approximately 2 times higher that under $B$ and $G$ (Figure $3 B$ ). There was no significant difference in the photosynthesis rate in the $R B$ group, whereas this value under $R_{8} G_{1} B_{1}$ and $R_{9} G_{1} B_{0}$ was higher than that under other treatments in the RGB group. In the W group, FL had a lower value compared to $\mathrm{NW}$, while the supplement of FR $\left(\mathrm{R}_{6} \mathrm{G}_{1} \mathrm{~B}_{3}+\mathrm{FR}\right.$ and $\left.\mathrm{NW}+\mathrm{FR}\right)$ showed no difference from treatments without $F R\left(R_{6} G_{1} B_{3}\right.$ and $\left.N W\right)$. Regarding transpiration rate, no significant difference was observed among the mono, $\mathrm{RB}$, and $\mathrm{W}$ groups (Figure $3 \mathrm{C}$ ). In the RGB group, $\mathrm{R}_{9} \mathrm{G}_{1} \mathrm{~B}_{0}$ had a higher transpiration rate than $R_{8} G_{1} B_{1}$, whereas in the FR group, $R_{6} G_{1} B_{3}+F R$ was $167 \%$ higher than $N W+F R$, and there was no significant difference in this value in $R_{6} G_{1} B_{3}+F R$ and $N W+F R$ compared to $R_{6} G_{1} B_{3}$ and $N W$, respectively. The conductance of $\mathrm{H}_{2} \mathrm{O}$ showed a similar trend to the transpiration rate, but there was no difference among all treatments (Figure 3D).

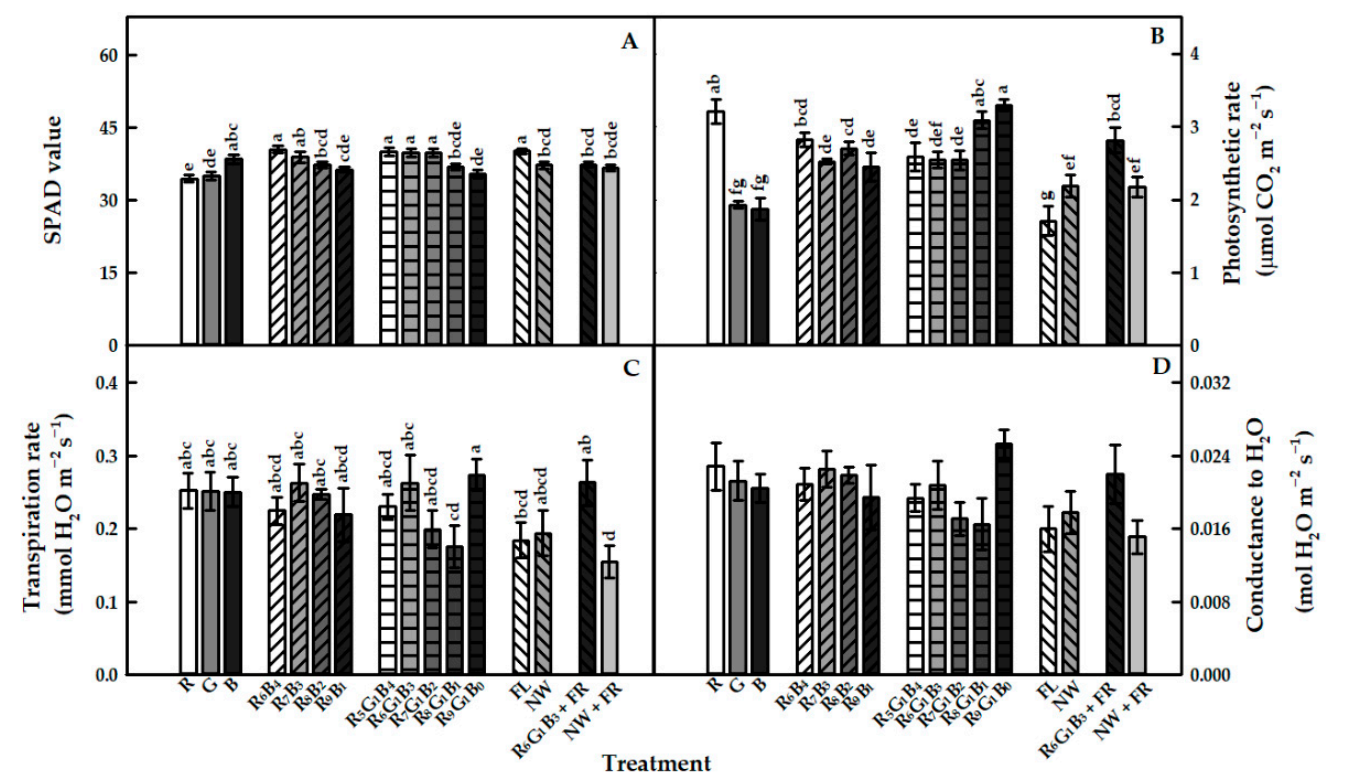

Figure 3. SPAD value (A) of ginseng sprouts at 5 weeks after planting and photosynthetic rate (B), transpiration rate $(\mathbf{C})$, and conductance to $\mathrm{H}_{2} \mathrm{O}(\mathbf{D})$ of ginseng sprouts grown under various light treatments at 4 weeks after planting. Different letters indicate significant differences at $p<0.05(n=4)$.

\subsection{Total Saponin Content}

The saponin content per gram of shoot dry weight (referred as shoot saponin content) under B was 1.95 and 1.34 times higher than that under R and G, respectively (Figure $4 A$ ). As the B ratio in RB and RGB groups increased, the shoot saponin content markedly enhanced. There was no significant difference in shoot saponin content in the W group. Supplemental FR was not effective in increasing shoot saponin content comparing to respective treatments without FR. The root saponin content per gram of root dry weight (referred as root saponin content) showed an opposite trend to the shoot saponin content (Figure 4B). Root saponin content under $R$ was slightly higher than that under B and $G$, and this value markedly increased with the increase in the R proportion in the RB group. In the RGB group, $R_{9} G_{1} B_{0}$ showed the highest value among treatments. There was no significant difference in root saponin content between the $W$ treatments. This value in $R_{6} G_{1} B_{3}+F R$ was lower than that in $R_{6} G_{1} B_{3}$, while NW + FR resulted in a higher value compared to NW. Total saponin content per plant dry weight 
(referred as total saponin content) showed a similar trend to shoot saponin content (Figure 4C). B and a higher ratio of B induced higher total saponin content. Interestingly, supplementing with FR was effective in enhancing the total saponin content.

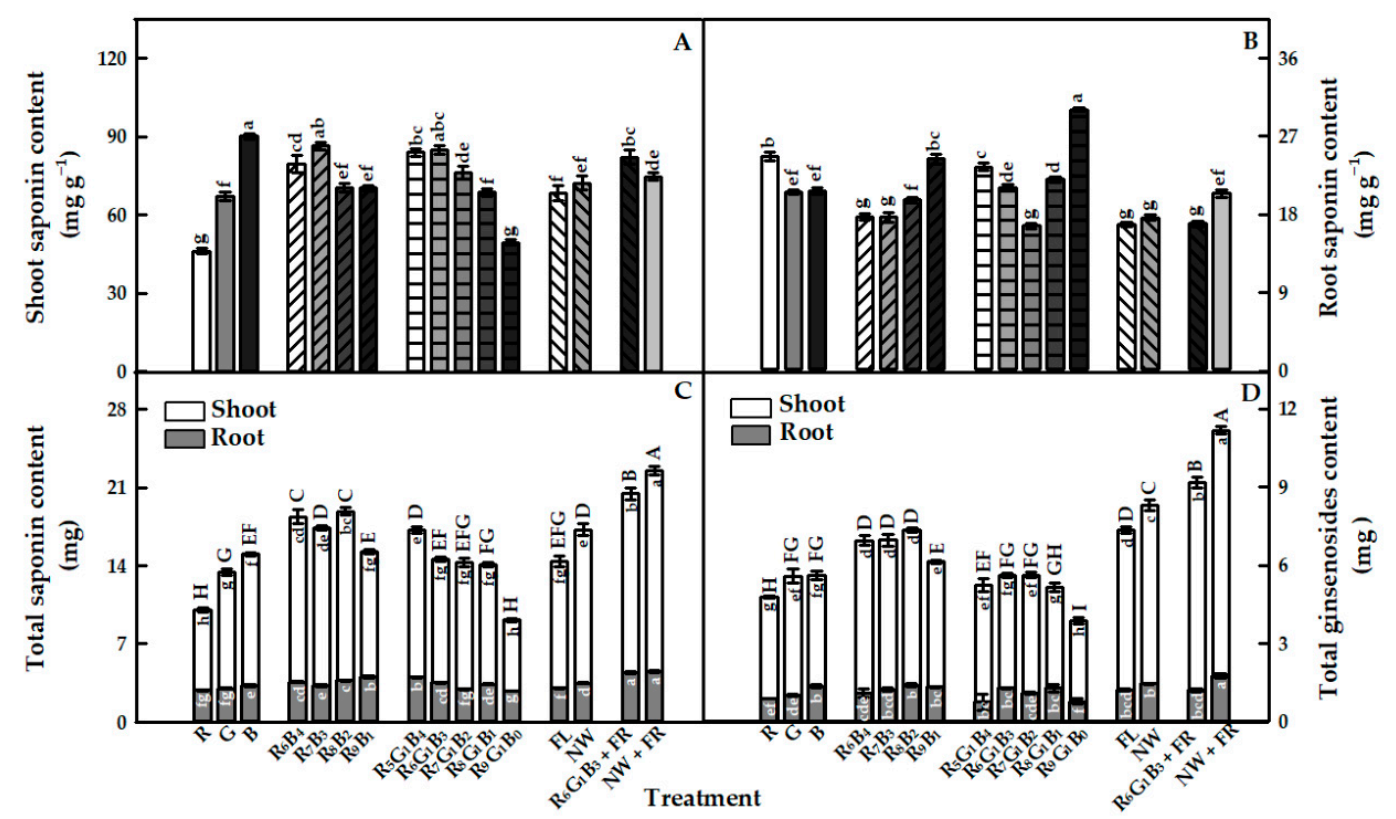

Figure 4. Shoot saponin content (A), root saponin content (B), total saponin content (C) and total ginsenosides content (D) of ginseng sprouts grown under various light treatments for 5 weeks. Different letters indicate a significant difference at $p<0.05$, and capital letters in figure $(\mathbf{C}, \mathbf{D})$ indicate a significant difference in total contents of shoot and root $(n=6)$.

\subsection{Ginsenosides Content}

For the ginsenosides content per gram of shoot dry weight (referred as shoot ginsenosides content), in the mono group, the total value was highest in $\mathrm{B}$, and this value was 1.55 times higher than that in $\mathrm{R}$ (Table 1). In particular, $\mathrm{Rb}_{1}$ and $\mathrm{Re}$, the major ginsenosides, in B were $238 \%$ and $295 \%$, respectively, higher than those in $\mathrm{R}$. In the RB group, $\mathrm{R}_{7} \mathrm{~B}_{3}$ showed higher $\mathrm{Rb}_{1}$ and Re compared to other treatments; the total value under $R_{7} B_{3}$ was 1.27 and 1.16 times higher than $R_{8} B_{2}$ and $R_{9} B_{1}$, respectively. In the RGB group, $\mathrm{Rb}_{1}, \mathrm{Rg}_{1}$, and $\mathrm{Re}$ in $\mathrm{R}_{6} \mathrm{G}_{1} \mathrm{~B}_{3}$ were $1.74,1.43$, and 1.68 times, respectively, higher than those in $R_{9} G_{1} B_{0}$. The $W$ group showed no significant differences in $R b_{1}, R_{1}$, and total value between treatments. In the supplement $F R, R_{6} G_{1} B_{3}+F R$ exhibited a higher total value than $R_{6} G_{1} B_{3}$ and was the highest value among all treatments; while NW + FR had no significant difference from NW, but this treatment also showed a very high value.

Regarding the ginsenosides content per gram of root dry weight (referred as root ginsenosides content), the total value in B was highest in mono group although there was no statistically significant difference compared to $\mathrm{R}$ (Table 2). The Re content under $\mathrm{B}$ was 4.21 and 5.15 times higher than that under $R$ and $G$, respectively. In the $R B$ group, $R_{9} B_{1}$ resulted in higher contents of major ginsenosides $R b_{1}$ and $R g_{1}$ compared to those under $R_{6} B_{4}$, which led to induce an increase in root ginsenosides content. In the RGB group, $R_{9} G_{1} B_{0}$ and $R_{8} G_{1} B_{1}$ showed higher values than $R_{7} G_{1} B_{2}$. There were no significant differences in $R_{1}, R_{1}$, and total value in $W$ group, whereas in the supplement $F R, R_{6} G_{1} B_{3}$ $+F R$ showed lower values compared to $R_{6} G_{1} B_{3}$, and no significant difference between $N W+F R$ and NW was obtained. The total ginsenosides content per plant dry weight (referred as total ginsenosides content) showed a similar trend to the total saponin content (Figure $4 \mathrm{D}$ ). $R$ and a high ratio of $R$ reduced the total ginsenosides content. The total ginsenosides contents in $R_{6} G_{1} B_{3}+F R$ and NW + FR were highest among all treatments with 9.18 and $11.17 \mathrm{mg}$, respectively; therefore, the supplement of FR was considerably effective in enhancing ginsenosides content. 
Table 1. Ginsenosides content of shoots in ginseng sprouts grown under various light treatments for 5 weeks.

\begin{tabular}{|c|c|c|c|c|c|c|c|c|c|c|c|c|c|c|c|c|c|c|c|c|c|c|}
\hline \multirow{3}{*}{ Group $^{1}$} & \multicolumn{22}{|c|}{ Shoot Ginsenosides Content $\left(\mathrm{mg} \mathrm{g}^{-1}\right)$} \\
\hline & \multirow{3}{*}{$\begin{array}{c}\text { Treatment } \\
\mathrm{R}\end{array}$} & \multicolumn{8}{|c|}{ Panaxadiol (PD) } & \multicolumn{10}{|c|}{ Panaxatriol (PT) } & \multirow{2}{*}{\multicolumn{2}{|c|}{ Total Value }} & \multirow{3}{*}{$\begin{array}{c}\mathbf{P D} / \mathbf{P T} \\
0.37\end{array}$} \\
\hline & & \multicolumn{2}{|c|}{$\mathbf{R b}_{1}$} & \multicolumn{2}{|c|}{$\mathbf{R b}_{2}$} & \multicolumn{2}{|c|}{ Rc } & \multicolumn{2}{|c|}{ Rd } & \multicolumn{2}{|c|}{$\mathrm{Rg}_{1}$} & \multicolumn{2}{|c|}{$\mathrm{Rg}_{2}$} & \multicolumn{2}{|c|}{$\mathbf{R g}_{3}$} & \multicolumn{2}{|c|}{$\operatorname{Re}$} & \multicolumn{2}{|c|}{$\mathrm{Rf}$} & & & \\
\hline \multirow{3}{*}{ Mono } & & 1.36 & $\mathrm{j}^{2}$ & 0.68 & fgh & 0.25 & gh & 3.34 & $\mathrm{fg}$ & 10.40 & $f$ & 1.02 & $\mathrm{~h}$ & 0.10 & $\mathrm{~h}$ & 3.65 & 1 & 0.14 & $\mathrm{f}$ & 20.93 & $\mathrm{j}$ & \\
\hline & G & 1.98 & hi & 1.18 & $\mathrm{~d}$ & 0.28 & bcde & 5.81 & bc & 13.93 & $\mathrm{~cd}$ & 1.67 & def & 0.12 & $\mathrm{~g}$ & 4.35 & $\mathrm{k}$ & 0.11 & $\mathrm{~g}$ & 29.44 & fgh & 0.46 \\
\hline & $\mathrm{B}$ & 3.25 & $\mathrm{bc}$ & 1.11 & de & 0.15 & $\mathrm{i}$ & 4.86 & $\mathrm{~d}$ & 10.43 & $\mathrm{f}$ & 1.58 & ef & 0.15 & ef & 10.78 & $\mathrm{a}$ & 0.24 & a & 32.55 & defg & 0.40 \\
\hline \multirow{4}{*}{ RB } & $\mathrm{R}_{6} \mathrm{~B}_{4}$ & 2.59 & $\mathrm{fg}$ & 1.49 & $\mathrm{c}$ & 0.27 & cdefg & 5.77 & $\mathrm{bc}$ & 13.71 & cde & 2.15 & $\mathrm{c}$ & 0.17 & de & 5.08 & ij & 0.11 & $\mathrm{~g}$ & 31.33 & efgh & 0.48 \\
\hline & $\mathrm{R}_{7} \mathrm{~B}_{3}$ & 3.11 & $\mathrm{~cd}$ & 1.20 & $\mathrm{~d}$ & 0.24 & $\mathrm{gh}^{\circ}$ & 4.84 & $\mathrm{~d}$ & 14.24 & bcd & 1.88 & cde & 0.14 & $\mathrm{fg}$ & 9.23 & $\mathrm{~b}$ & 0.21 & bcd & 35.10 & bcde & 0.37 \\
\hline & $\mathrm{R}_{8} \mathrm{~B}_{2}$ & 2.39 & $\mathrm{~g}$ & 0.97 & de & 0.29 & $\mathrm{bc}$ & 3.79 & ef & 12.98 & de & 1.57 & ef & 0.15 & ef & 5.40 & $\mathrm{i}$ & 0.15 & $\mathrm{f}$ & 27.69 & hi & 0.37 \\
\hline & $\mathrm{R}_{9} \mathrm{~B}_{1}$ & 2.52 & $\mathrm{~g}$ & 0.89 & ef & 0.29 & bc & 4.02 & $\mathrm{e}$ & 14.10 & bcd & 1.45 & $\mathrm{fg}$ & 0.16 & de & 6.49 & $\mathrm{fg}$ & 0.21 & bcd & 30.13 & fgh & 0.34 \\
\hline \multirow{5}{*}{ RGB } & $\mathrm{R}_{5} \mathrm{G}_{1} \mathrm{~B}_{4}$ & 2.87 & de & 0.44 & hi & 0.25 & gh & 2.40 & $\mathrm{~h}$ & 14.89 & $\mathrm{bc}$ & 1.00 & $\mathrm{~h}$ & 0.18 & $\mathrm{~cd}$ & 6.24 & $\mathrm{~g}$ & 0.16 & ef & 28.42 & gh & 0.26 \\
\hline & $\mathrm{R}_{6} \mathrm{G}_{1} \mathrm{~B}_{3}$ & 3.05 & $\mathrm{~cd}$ & 0.54 & ghi & 0.30 & $\mathrm{~b}$ & 2.83 & gh & 17.17 & $\mathrm{a}$ & 1.06 & $\mathrm{~h}$ & 0.17 & $\mathrm{~cd}$ & 7.77 & d & 0.19 & cde & 33.08 & cdef & 0.26 \\
\hline & $\mathrm{R}_{7} \mathrm{G}_{1} \mathrm{~B}_{2}$ & 2.78 & ef & 0.50 & ghi & 0.25 & fgh & 2.59 & $\mathrm{~h}$ & 14.30 & bcd & 1.10 & $\mathrm{~h}$ & 0.21 & $\mathrm{ab}$ & 8.30 & $\mathrm{c}$ & 0.21 & $a b c$ & 30.24 & fgh & 0.25 \\
\hline & $\mathrm{R}_{8} \mathrm{G}_{1} \mathrm{~B}_{1}$ & 2.10 & $\mathrm{~h}$ & 0.31 & i & 0.26 & defgh & 1.81 & $\mathrm{i}$ & 13.24 & cde & 0.64 & $\mathrm{i}$ & 0.18 & $\mathrm{~cd}$ & 6.01 & gh & 0.21 & $a b c$ & 24.77 & $\mathrm{j}$ & 0.22 \\
\hline & $\mathrm{R}_{9} \mathrm{G}_{1} \mathrm{~B}_{0}$ & 1.75 & $\mathrm{i}$ & 0.71 & $\mathrm{fg}$ & 0.26 & efgh & 3.49 & ef & 12.02 & ef & 1.15 & gh & 0.14 & $\mathrm{fg}$ & 4.63 & $\mathrm{jk}$ & 0.15 & $\mathrm{f}$ & 24.30 & $\mathrm{ij}$ & 0.34 \\
\hline \multirow{2}{*}{ W } & FL & 3.12 & de & 1.14 & $\mathrm{c}$ & 0.24 & $\mathrm{a}$ & 5.34 & $\mathrm{~b}$ & 15.90 & $\mathrm{a}$ & 1.69 & $\mathrm{~cd}$ & 0.17 & $a$ & 9.07 & hi & 0.23 & ef & 36.89 & bcd & 0.36 \\
\hline & NW & 2.93 & $\mathrm{~cd}$ & 1.44 & d & 0.33 & $\mathrm{~h}$ & 6.07 & $\mathrm{~cd}$ & 17.32 & $a b$ & 1.94 & def & 0.21 & cde & 5.61 & $\mathrm{~b}$ & 0.16 & $a b$ & 36.02 & $\mathrm{bc}$ & 0.43 \\
\hline \multirow{2}{*}{ FR } & $\mathrm{R}_{6} \mathrm{G}_{1} \mathrm{~B}_{3}+\mathrm{FR}$ & 3.50 & $\mathrm{a}$ & 2.52 & $\mathrm{a}$ & 0.27 & cdef & 7.88 & $\mathrm{a}$ & 15.90 & $a b$ & 3.50 & $\mathrm{a}$ & 0.19 & $\mathrm{bc}$ & 7.08 & $\mathrm{e}$ & 0.19 & cde & 41.03 & $\mathrm{a}$ & 0.53 \\
\hline & NW + FR & 3.40 & $a b$ & 1.77 & $\mathrm{~b}$ & 0.29 & bcd & 6.17 & $\mathrm{~b}$ & 17.44 & $\mathrm{a}$ & 2.54 & $\mathrm{~b}$ & 0.18 & $\mathrm{~cd}$ & 6.90 & ef & 0.18 & de & 38.87 & $a b$ & 0.43 \\
\hline
\end{tabular}

${ }^{1}$ Light treatments with red LEDs (R), green LEDs (G), blue LEDs (B), fluorescent lamps (FL), natural white LEDs (NW), and far-red LEDs (FR), ${ }^{2}$ Mean separation within columns according to Duncan's multiple range test at $p<0.05(n=5)$. 
Table 2. Ginsenosides content of roots in ginseng sprouts grown under various light treatments for 5 weeks.

\begin{tabular}{|c|c|c|c|c|c|c|c|c|c|c|c|c|c|c|c|c|c|c|c|c|}
\hline \multirow{4}{*}{ Group $^{1}$} & \multicolumn{20}{|c|}{ Root Ginsenosides Content $\left(\mathrm{mg} \mathrm{g}^{-1}\right)$} \\
\hline & \multirow{3}{*}{$\begin{array}{c}\text { Treatment } \\
\mathrm{R}\end{array}$} & \multicolumn{8}{|c|}{ Panaxadiol (PD) } & \multicolumn{8}{|c|}{ Panaxatriol (PT) } & \multirow{2}{*}{\multicolumn{2}{|c|}{ Total Value }} & \multirow{3}{*}{$\begin{array}{r}\text { PD/PT } \\
0.42\end{array}$} \\
\hline & & \multicolumn{2}{|c|}{$\mathbf{R} \mathbf{b}_{1}$} & \multicolumn{2}{|c|}{$\mathbf{R b}_{2}$} & \multicolumn{2}{|c|}{ Rc } & \multicolumn{2}{|c|}{ Rd } & \multicolumn{2}{|c|}{$\mathbf{R g}_{1}$} & \multicolumn{2}{|c|}{$\mathbf{R g}_{2}$} & \multicolumn{2}{|c|}{$\operatorname{Re}$} & \multicolumn{2}{|c|}{$\mathrm{Rf}$} & & & \\
\hline & & 1.15 & $a b c^{2}$ & 0.60 & cdef & 0.12 & bcdef & 0.33 & cdefg & 3.86 & $a b c$ & 0.72 & $\mathrm{a}$ & 0.33 & c & 0.34 & $\mathrm{bc}$ & 7.45 & $a b c$ & \\
\hline Mono & B & 1.14 & $a b c$ & 0.83 & $\mathrm{a}$ & 0.10 & def & 0.31 & defg & 3.00 & def & 0.77 & $\mathrm{a}$ & 1.39 & $\mathrm{a}$ & 0.52 & $\mathrm{a}$ & 8.06 & $\mathrm{a}$ & 0.42 \\
\hline \multirow{4}{*}{$\mathrm{RB}$} & $\mathrm{R}_{6} \mathrm{~B}_{4}$ & 0.65 & $\mathrm{f}$ & 0.39 & $\mathrm{i}$ & 0.13 & bcdef & 0.29 & efg & 2.26 & $\mathrm{fg}$ & 0.36 & $\mathrm{~d}$ & 0.27 & c & 0.34 & $\mathrm{bc}$ & 4.69 & $\mathrm{e}$ & 0.45 \\
\hline & $\mathrm{R}_{7} \mathrm{~B}_{3}$ & 0.91 & de & 0.50 & fgh & 0.07 & ef & 0.32 & cdefg & 2.79 & efg & 0.53 & $\mathrm{e}$ & 0.98 & $\mathrm{~b}$ & 0.42 & $\mathrm{ab}$ & 6.52 & $\mathrm{bcd}$ & 0.38 \\
\hline & $\mathrm{R}_{8} \mathrm{~B}_{2}$ & 0.91 & de & 0.54 & efg & 0.13 & bcde & 0.36 & bcde & 3.21 & bcde & 0.57 & $\mathrm{bc}$ & 0.28 & c & 0.29 & $\mathrm{~cd}$ & 6.29 & $\mathrm{~cd}$ & 0.45 \\
\hline & $\mathrm{R}_{9} \mathrm{~B}_{1}$ & 1.29 & $\mathrm{a}$ & 0.72 & $\mathrm{~b}$ & 0.17 & $a b c$ & 0.42 & a & 3.44 & abcde & 0.78 & $\mathrm{a}$ & 0.35 & c & 0.34 & $\mathrm{bc}$ & 7.51 & $a b c$ & 0.53 \\
\hline \multirow{5}{*}{ RGB } & $\mathrm{R}_{5} \mathrm{G}_{1} \mathrm{~B}_{4}$ & 1.11 & abcd & 0.71 & $\mathrm{bc}$ & 0.21 & $\mathrm{a}$ & 0.40 & $\mathrm{ab}$ & 3.31 & bcde & 0.74 & $\mathrm{a}$ & 0.27 & c & 0.27 & $\mathrm{~cd}$ & 7.02 & abcd & 0.53 \\
\hline & $\mathrm{R}_{6} \mathrm{G}_{1} \mathrm{~B}_{3}$ & 1.16 & $a b$ & 0.67 & bcd & 0.17 & abcd & 0.33 & cdefg & 3.43 & abcde & 0.68 & $a b$ & 0.34 & c & 0.30 & bcd & 7.06 & abcd & 0.49 \\
\hline & $\mathrm{R}_{7} \mathrm{G}_{1} \mathrm{~B}_{2}$ & 0.91 & de & 0.54 & ef & 0.12 & bcdef & 0.27 & $\mathrm{~g}$ & 2.84 & defg & 0.56 & $\mathrm{bc}$ & 0.47 & c & 0.25 & $\mathrm{~cd}$ & 5.96 & $\mathrm{~d}$ & 0.45 \\
\hline & $\mathrm{R}_{8} \mathrm{G}_{1} \mathrm{~B}_{1}$ & 1.24 & $\mathrm{a}$ & 0.72 & $\mathrm{~b}$ & 0.17 & $\mathrm{ab}$ & 0.36 & abcd & 4.14 & $\mathrm{a}$ & 0.76 & $\mathrm{a}$ & 0.32 & c & 0.33 & $\mathrm{bc}$ & 8.04 & $\mathrm{a}$ & 0.45 \\
\hline & $\mathrm{R}_{9} \mathrm{G}_{1} \mathrm{~B}_{0}$ & 1.25 & a & 0.73 & $\mathrm{~b}$ & 0.12 & bcdef & 0.34 & bcdef & 3.92 & $\mathrm{ab}$ & 0.75 & $\mathrm{a}$ & 0.33 & c & 0.31 & bcd & 7.77 & $\mathrm{ab}$ & 0.46 \\
\hline \multirow{2}{*}{ W } & FL & 0.99 & bcd & 0.67 & bcde & 0.10 & $\mathrm{bcd}$ & 0.31 & $a b c$ & 2.85 & cde & 0.74 & $a b$ & 0.42 & c & 0.28 & $\mathrm{~cd}$ & 6.37 & bcd & 0.48 \\
\hline & NW & 1.00 & bcd & 0.64 & $\mathrm{bcd}$ & 0.14 & cdef & 0.38 & defg & 3.11 & defg & 0.69 & $\mathrm{a}$ & 0.25 & c & 0.23 & $\mathrm{~cd}$ & 6.44 & bcd & 0.50 \\
\hline \multirow{2}{*}{ FR } & $\mathrm{R}_{6} \mathrm{G}_{1} \mathrm{~B}_{3}+\mathrm{FR}$ & 0.72 & ef & 0.40 & hi & 0.06 & $\mathrm{f}$ & 0.27 & $\mathrm{~g}$ & 2.17 & $\mathrm{~g}$ & 0.40 & $\mathrm{~d}$ & 0.43 & c & 0.19 & $\mathrm{~d}$ & 4.65 & e & 0.45 \\
\hline & NW + FR & 0.93 & $\mathrm{~cd}$ & 0.57 & def & 0.15 & abcd & 0.33 & cdefg & 2.89 & defg & 0.57 & $\mathrm{bc}$ & 0.28 & c & 0.28 & $\mathrm{~cd}$ & 6.01 & d & 0.49 \\
\hline
\end{tabular}

${ }^{1}$ Light treatments with red LEDs (R), green LEDs (G), blue LEDs (B), fluorescent lamps (FL), natural white LEDs (NW), and far-red LEDs (FR); ${ }^{2}$ Mean separation within columns according to Duncan's multiple range test at $p<0.05(\mathrm{n}=5)$. 


\section{Discussion}

\subsection{Growth Characteristics}

In this study, $\mathrm{R}$ and the higher ratio of $\mathrm{R}$ in LEDs treatments had a positive effect on shoot growth of ginseng sprouts, which was considered due to the high light utilization efficiency of red light. Many studies proved that red light promotes plant biomass such as fresh and dry weights, plant height, and leaf area [23]. In the present study, the leaf area and stem length showed a similar pattern to the shoot fresh weight; therefore, it can be considered that they were the main factors in determining the total fresh weight. Meanwhile, monochromatic B suppresses hypocotyl elongation compared to monochromatic R, and the high proportion of B decreases the stem length [24]. In this study, $R$ and $B$ lights also showed a contrasting effect on stem growth. The higher ratio of $\mathrm{R}$ light resulted in a higher stem length. This was consistent with the results of previous studies on the growth of various crops under the combination of red and blue [20,25].

In the $\mathrm{W}$ group, although FL and NW had different light spectra, the ratio of $\mathrm{R}, \mathrm{G}$, and $\mathrm{B}$ light were almost the same at 28:44:27 and 29:48:23 (data not shown), respectively; therefore, it seemed not to be significantly different. Likewise, $\mathrm{G}$ light also did not show the positive effect on ginseng growth. Green light has a lower absorbance and higher transmittance and reflectance than other wavelengths, showing inefficiently impacts on the growth and development as well as photosynthesis of plants [26], which was observed in the present study with the lower photosynthesis rate under green light. In contrast, the supplement of FR LEDs increased both shoot and root of the ginseng sprouts, especially in leaf area, which corresponded to previous studies that showed a growth-promoting effect in lettuce and Crepidiastrum denticulatum [25,27]. The ratio of R/FR used in this experiment (1.2) was similar to the value during solar noon, resulting in greater plant height, internode length, and node number, which contributed to higher plant fresh weight in many crops [25,27]. However, although FR LEDs presented a higher ginseng sprouts growth, it was not effective on the stem length. Noticeably, in dicotyledonous plants, the low R/FR (in a shaded environment) results in the rapid elongation of the stem [28-30]. Since ginseng is a shade plant, the stem growth caused by the shade avoidance response did not occur in the FR group. Park and Runkle reported that shade-avoidant plants such as geranium, petunia, and snapdragon showing sensitive changes in stem length according to phytochrome photoequilibrium (PPE) directly affected by the R/FR ratio, but impatiens, a shade-tolerant plant, was not responsive [31]. In this study, both supplemental FR treatments showed significantly higher leaf area compared to the respective treatments without FR; therefore, FR light was effective in enhancing the leaf area of ginseng sprouts.

Regarding root growth of ginseng sprouts, since the cultivation period ( 5 weeks) of this experiment was not enough for the transportation of the nutrients produced from leave to the root, the difference in root weight according to visible light treatments seemed to be insignificant. Supplemental FR treatment increased the root fresh weight. Gelderen et al. stated that the auxin and gibberellic acid produced under FR in shoots may move toward the roots, which led to a positive effect on root development [32]. In general, the total fresh weight was similar to the shoot fresh weight because the change in shoot fresh weight was much greater than that of the root fresh weight according to light treatments. The $T / R$ ratio was also comparable to the pattern of the shoot fresh weight. Both treatments with supplemented FR showed a T/R ratio of approximately 1 by significantly improving root growth.

\subsection{Photosynthetic Parameters}

The results of photosynthetic parameters supported the growth of ginseng sprouts. In the monochromatic and RGB groups, the positive effect of $\mathrm{R}$ light on enhancing the photosynthetic rate was confirmed. McCree also reported that red light resulted in higher photosynthetic efficiency compared to blue light [33]. Therefore, the treatments with a high ratio of red light increased the photosynthesis rate, which was thought to have a major effect on the increase in total fresh weight. Meanwhile, FR light had little impact on the improvement of the photosynthesis rate per unit leaf area, but it resulted in the 
expansion of the leaf area, which led to an increase in the photosynthetic rate and fresh weight of the whole plant. The transpiration rate and conductance of $\mathrm{H}_{2} \mathrm{O}$ increased as the $\mathrm{B}$ ratio increased in the combination groups. Although there was a difference in the chlorophyll content (SPAD value) according to the light treatments, the difference did not contribute to the photosynthetic rate. The SPAD value increased as the ratio of $B$ increased. In general, blue light induces an increase in tetrapyrrole precursor 5-aminolevulinic acid, which improves chlorophyll biosynthesis, whereas red light downregulates protein and gene expression of enzymes involved in chlorophyll biosynthesis [34,35]. Supplemental FR light did not affect the SPAD value. Shade-tolerant plant species, such as impatiens, adapted even in FR light environments and showed normal photosynthesis without reducing chlorophyll content [36].

\subsection{Total Saponin and Ginsenosides Contents}

It is well known that the type and efficient production of bioactive compounds in ginseng are mostly dependent on the tissues and the plant's age [37]. The recent studies prove that the accumulation of saponin and ginsenosides produced in ginseng is considerably affected by environmental conditions [38]. $B$ light was reported to enhance the content of secondary metabolites than $R$ light in several crops [12,39], which was consistent with results of the present study with the increase in shoot saponin content, total saponin content, and shoot ginsenosides content under B. A high proportion of B particularly enhanced the major ginsenosides $\mathrm{Rb}_{1}, \mathrm{Rg}_{1}$, and $\mathrm{Re}$, which led to an increase in the total ginsenosides content. In contrast, Fournier et al. reported that $\mathrm{R}$ contributed to the increase of $\mathrm{Rd}$ and $\mathrm{Rg}_{1}$ in 2-year-old American ginseng, but B did not affect ginsenosides accumulation [40]. The root saponin content was higher as the ratio of $\mathrm{R}$ increased, which might be explained by the differentiated distribution of assimilates to shoot and root according to light quality. In general, it is easy to have a dilution effect, such as a decrease in the concentration of secondary metabolites per unit dry weight due to growth promotion [27].

The supplemental FR light increased the growth of ginseng sprouts as well as saponin and ginsenosides content in ginseng sprouts. These results corresponded to previous study reporting that FR light resulted in the variation in ginsenosides contents and the higher levels of FR light increased ginsenosides production [40]. The root ginsenosides content also showed the same tendency as the root saponin content, which was different from that in the shoot. The ratio of PD/PT showed a difference between shoot and root in the RGB and $\mathrm{W}$ groups that contained green light. The effect of light quality on ginsenosides synthesis is unclear, but it shows the possibility that PD/PT may vary depending on the light quality. The total ginsenosides content was similar to the pattern of the shoot ginsenosides content because the shoot was about 4.4 times higher than that of the root.

\section{Conclusions}

According to the results of this study, $\mathrm{R}$ light was effective on enhancing growth characteristics as well as photosynthesis parameters, while B light had a positive effect on improving the total saponin and ginsenosides content. The supplemental far-red light did not affect the stem length in ginseng sprouts, but it improved the leaf area and induced balanced growth between the shoot and root. This growth improvement by supplemental FR light led to an increase in total saponin and ginsenosides content. In particular, NW + FR was the most effective treatment. These results suggest that the growth and ginsenosides content of ginseng sprouts can be enhanced according to the composition of light quality. These findings can be applied to ensure the economic efficiency of ginseng sprout production.

Supplementary Materials: The following are available online at http://www.mdpi.com/2073-4395/10/12/1979/s1, Figure S1: Ginseng seedlings were cultivated under various light treatments for 5 weeks.

Author Contributions: Conceptualization, methodology; software, formal analysis, investigation, resources, data curation, writing —original draft preparation, Y.-J.K. and T.K.L.N.; supervision, validation, funding acquisition, writing-review and editing, M.-M.O. All authors have read and agreed to the published version of the manuscript.

Funding: This work was carried out with the support of Cooperative Research Program for Agriculture Science and Technology Development (project no. PJ01385201) Rural Development Administration, Korea. 
Acknowledgments: In this section you can acknowledge any support given which is not covered by the author contribution or funding sections. This may include administrative and technical support, or donations in kind (e.g., materials used for experiments).

Conflicts of Interest: Authors declare no conflict of interest.

\section{References}

1. Kim, D.H.; Moon, Y.S.; Lee, T.H.; Jung, J.S.; Suh, H.W.; Song, D.K. The inhibitory effect of ginseng saponins on the stress-induced plasma interleukin-6 level in mice. J. Neurosci. Lett. 2003, 353, 13-16. [CrossRef] [PubMed]

2. López, M.V.N.; Cuadrado, M.P.G.-S.; Ruiz-Poveda, O.M.P.; Del Fresno, A.M.V.; Accame, M.E.C. Neuroprotective effect of individual ginsenosides on astrocytes primary culture. Biochim. Biophys. Acta Gen. Subj. 2007, 1770, 1308-1316. [CrossRef] [PubMed]

3. Vuksan, V.; Sung, M.-K.; Sievenpiper, J.L.; Stavro, P.M.; Jenkins, A.L.; Di Buono, M.; Lee, K.-S.; Leiter, L.A.; Nam, K.Y.; Arnason, J.T.; et al. Korean red ginseng (Panax ginseng) improves glucose and insulin regulation in well-controlled, type 2 diabetes: Results of a randomized, double-blind, placebo-controlled study of efficacy and safety. Nutr. Metab. Cardiovasc. Dis. 2008, 18, 46-56. [CrossRef] [PubMed]

4. Chen, F.; Luo, J.-G.; Kong, L. Determination of 10 ginsenosides in Panax ginseng of different harvest times based on HPLC fingerprints and principal component analysis. Nat. Prod. Res. 2013, 27, 851-854. [CrossRef] [PubMed]

5. Li, X.G.; Yan, Y.Z.; Jin, X.; Kim, Y.K.; Uddin, M.R.; Kim, Y.B.; Bae, H.; Kim, Y.C.; Lee, S.W.; Park, S.U. Ginsenoside content in the leaves and roots of Panax ginseng at different ages. Life Sci. 2012, 9, 670-683.

6. Kim, G.S.; Hyun, D.Y.; Kim, Y.O.; Lee, S.E.; Kwon, H.; Cha, S.W.; Park, C.B.; Kim, Y.B. Investigation of ginsenosides in different parts of Panax ginseng cultured by hydroponics. Korean J. Hortic. Sci. 2010, 28, 216-226.

7. Choi, S.Y.; Cho, C.-W.; Lee, Y.-M.; Kim, S.-S.; Lee, S.-H.; Kim, K.-T. Comparison of Ginsenoside and Phenolic Ingredient Contents in Hydroponically-cultivated Ginseng Leaves, Fruits, and Roots. J. Ginseng. Res. 2012, 36, 425-429. [CrossRef]

8. Kozai, T. Resource use efficiency of closed plant production system with artificial light: Concept, estimation and application to plant factory. Proc. Jpn. Acad. Ser. B 2013, 89, 447-461. [CrossRef]

9. Bian, Z.H.; Yang, Q.C.; Liu, W.K. Effects of light quality on the accumulation of phytochemicals in vegetables produced in controlled environments: A review. J. Sci. Food Agric. 2015, 95, 869-877. [CrossRef]

10. Schmitt, J.; Wulff, R.D. Light spectral quality, phytochrome and plant competition. Trends Ecol. Evol. 1993, 8, 47-51. [CrossRef]

11. Smith, H. Light Quality, Photoperception, and Plant Strategy. Annu. Rev. Plant Physiol. 1982, 33, 481-518. [CrossRef]

12. Son, K.-H.; Oh, M.M. Leaf Shape, Growth, and Antioxidant Phenolic Compounds of Two Lettuce Cultivars Grown under Various Combinations of Blue and Red Light-emitting Diodes. HortScience 2013, 48, 988-995. [CrossRef]

13. Kozai, T. Smart Plant Factory: The Next Generation Indoor Vertical Farms, 1st ed.; Springer: Berlin/Heidelberg, Germany, 2018; pp. 3-14.

14. Jeon, Y.-M.; Son, K.-H.; Kim, S.-M.; Oh, M.M. Growth and bioactive compounds as affected by irradiation with various spectrum of light-emitting diode lights in dropwort. Hortic. Environ. Biotechnol. 2017, 58, 467-478. [CrossRef]

15. Kim, E.-Y.; Park, S.-A.; Park, B.-J.; Lee, Y.; Oh, M.M. Growth and antioxidant phenolic compounds in cherry tomato seedlings grown under monochromatic light-emitting diodes. Hortic. Environ. Biotechnol. 2014, 55, 506-513. [CrossRef]

16. Lee, J.W.; Son, K.H.; Lee, J.H.; Kim, Y.J.; Oh, M.M. Growth and Biochemical Responses of Ice Plant Irradiated by Various Visible Light Spectra in Plant Factories. Hortic. Sci. Technol. 2019, 37, 598-608.

17. Carvalho, R.F.; Takaki, M.; Azevedo, R.A. Plant pigments: The many faces of light perception. Acta Physiol. Plant. 2010, 33, 241-248. [CrossRef] 
18. Sullivan, J.A.; Deng, X.-W. From seed to seed: The role of photoreceptors in Arabidopsis development. Dev. Biol. 2003, 260, 289-297. [CrossRef]

19. Li, J.; Hikosaka, S.; Goto, E. Effects of light quality and photosynthetic photon flux on growth and carotenoid pigments in spinach (Spinacia oleracea L.). Acta Hortic. 2011, 105-110. [CrossRef]

20. Pennisi, G.; Blasioli, S.; Cellini, A.; Maia, L.; Crepaldi, A.; Braschi, I.; Spinelli, F.; Nicola, S.; Fernandez, J.A.; Stanghellini, C.; et al. Unraveling the Role of Red:Blue LED Lights on Resource Use Efficiency and Nutritional Properties of Indoor Grown Sweet Basil. Front. Plant Sci. 2019, 10, 305. [CrossRef]

21. Zhang, X.; He, D.; Niu, G.; Yan, Z.; Song, J. Effects of environment lighting on the growth, photosynthesis, and quality of hydroponic lettuce in a plant factory. Int. J. Agric. Biol. Eng. 2018, 11, 33-40. [CrossRef]

22. Hiai, S.; Oura, H.; Nakajima, T. Color reaction of some sapogenins and saponins with vanillin and sulfur1c acid. Planta Med. 1976, 29, 116-122. [CrossRef]

23. Wang, J.; Lu, W.; Tong, Y.; Yang, Q. Leaf Morphology, Photosynthetic Performance, Chlorophyll Fluorescence, Stomatal Development of Lettuce (Lactuca sativa L.) Exposed to Different Ratios of Red Light to Blue Light. Front. Plant Sci. 2016, 7, 250. [CrossRef] [PubMed]

24. Nanya, K.; Ishigami, Y.; Hikosaka, S.; Goto, E. Effects of blue and red light on stem elongation and flowering of tomato seedlings. Acta Hortic. 2012, 956, 261-266. [CrossRef]

25. Bae, J.-H.; Park, S.-Y.; Oh, M.M. Supplemental irradiation with far-red light-emitting diodes improves growth and phenolic contents in Crepidiastrum denticulatum in a plant factory with artificial lighting. Hortic. Environ. Biotechnol. 2017, 58, 357-366. [CrossRef]

26. Folta, K.M.; Maruhnich, S.A. Green light: A signal to slow down or stop. J. Exp. Bot. 2007, 58, $3099-3111$. [CrossRef] [PubMed]

27. Lee, M.-J.; Son, K.-H.; Oh, M.M. Increase in biomass and bioactive compounds in lettuce under various ratios of red to far-red LED light supplemented with blue LED light. Hortic. Environ. Biotechnol. 2016, 57, 139-147. [CrossRef]

28. Morgan, D.C.; Smith, H. Linear relationship between phytochrome photoequilibrium and growth in plants under simulated natural radiation. Nat. Cell Biol. 1976, 262, 210-212. [CrossRef]

29. Morgan, D.C.; Smith, H. The relationship between phytochrome-photoequilibrium and Development in light grown Chenopodium album L. Planta 1978, 142, 187-193. [CrossRef]

30. Child, R.; Morgan, D.C.; Smith, H. Control of development in Chenopodium album 1. by shadelight: The effect of light quality (red:far-red ratio) on morphogenesis. New Phytol. 1981, 89, 545-555. [CrossRef]

31. Park, Y.; Runkle, E.S. Far-red radiation promotes growth of seedlings by increasing leaf expansion and whole-plant net assimilation. Environ. Exp. Bot. 2017, 136, 41-49. [CrossRef]

32. Van Gelderen, K.; Kang, C.; Pierik, R. Light Signaling, Root Development, and Plasticity. Plant Physiol. 2018, 176, 1049-1060. [CrossRef] [PubMed]

33. McCree, $\mathrm{K}$. Test of current definitions of photosynthetically active radiation against leaf photosynthesis data. Agric. Meteorol. 1972, 10, 443-453. [CrossRef]

34. Sood, S.; Gupta, V.; Tripathy, B.C. Photoregulation of the Greening Process of Wheat Seedlings Grown in Red Light. Plant Mol. Biol. 2005, 59, 269-287. [CrossRef] [PubMed]

35. Tanaka, A.; Ito, H.; Tanaka, R.; Tanaka, N.K.; Yoshida, K.; Okada, K. Chlorophyll a oxygenase (CAO) is involved in chlorophyll b formation from chlorophyll a. Proc. Natl. Acad. Sci. USA 1998, 95, 12719-12723. [CrossRef]

36. Park, Y.; Runkle, E.S. Far-red radiation and photosynthetic photon flux density independently regulate seedling growth but interactively regulate flowering. Environ. Exp. Bot. 2018, 155, 206-216. [CrossRef]

37. Shi, W.; Wang, Y.; Li, J.; Zhang, H.; Ding, L. Investigation of ginsenosides in different parts and ages of Panax ginseng. Food Chem. 2007, 102, 664-668. [CrossRef]

38. Lim, W.; Mudge, K.W.; Vermeylen, F. Effects of Population, Age, and Cultivation Methods on Ginsenoside Content of Wild American Ginseng (Panax quinquefolium). J. Agric. Food Chem. 2005, 53, 8498-8505. [CrossRef]

39. Lee, J.G.; Oh, S.S.; Cha, S.H.; Jang, Y.A.; Kim, S.Y.; Um, Y.C.; Cheong, S.R. Effects of red/blue light ratio and short-term light quality conversion on growth and anthocyanin contents of baby leaf lettuce. Prot. Hortic. Plant Fact. 2010, 19, 351-359. 
40. Fournier, A.R.; Proctor, J.T.; Gauthier, L.; Khanizadeh, S.; Bélanger, A.; Gosselin, A.; Dorais, M. Understory light and root ginsenosides in forest-grown Panax quinquefolius. Phytochemistry 2003, 63, 777-782. [CrossRef]

Publisher's Note: MDPI stays neutral with regard to jurisdictional claims in published maps and institutional affiliations.

(C) 2020 by the authors. Licensee MDPI, Basel, Switzerland. This article is an open access article distributed under the terms and conditions of the Creative Commons Attribution (CC BY) license (http://creativecommons.org/licenses/by/4.0/). 